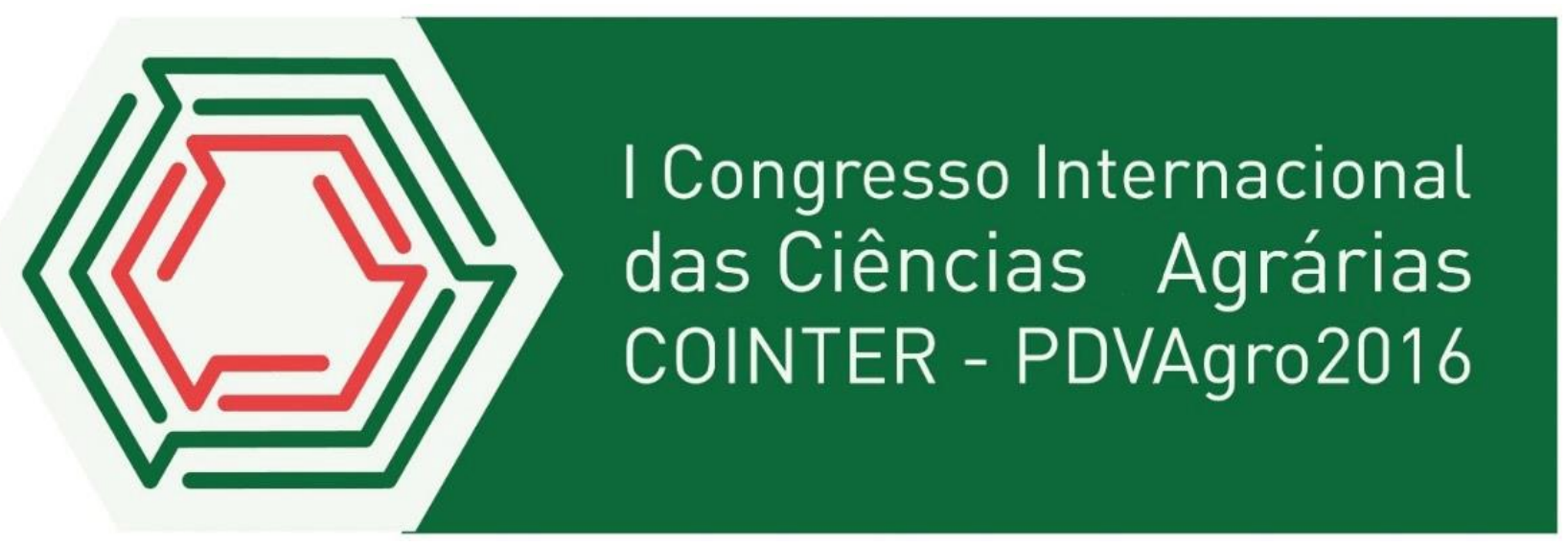

\title{
CRESCIMENTO DE REGENERANTES DE Commiphora leptophoeos (MART.) J.B. GILLETT (BURSERACEAE) EM FUNÇÃO DA IDADE DA FLORESTA
}

Vanessa Kelly Rodrigues de Araujo ${ }^{1}$; Josiene Maria Falcão Fraga dos santos ${ }^{2}$; Rejane Magalhães de Mendonça Pimentel ${ }^{2}$; Elcida de Lima Araújoº ${ }^{2}$ Kleber Andrade da Silva ${ }^{3}$

\section{Introdução}

Florestas jovens, que voltam a se restabelecer após perturbação, apresentam diferenças em suas condições ambientais quando comparadas as florestas maduras, as quais apresentam a estrutura da copa das árvores mais fechada, proporcionando maiores taxas de umidade e sombreamento no sub-bosque (LOPES et al., 2012; PEREIRA et al., 2001).

Tais variações nas condições ambientais das florestas podem influenciar o desenvolvimento das plantas (ARAÚJO et al., 2008a). Além disso, pode atuar sobre as concentrações dos macronutrientes nas folhas, podendo assim alterar alguns processos fisiológicos das plantas, como a fotossíntese e, consequentemente, o crescimento e sobrevivência das mesmas no ambiente (DOLOSO et al., 2009; ZHU et al., 2013).

Assim, estudos que investiguem repostas do desenvolvimento e crescimento de plantas sobre diferentes condições ambientais encontradas entre florestas jovem, com histórico de perturbação, e florestas maduras, sem histórico de perturbação, são importantes para compreensão dos diferentes comportamentos das espécies, bem como, da resiliência dessas florestas. Além de, poder auxilia trabalhos de recuperação de florestas tropicais secas que foram degradadas.

Nesse contexto, o presente estudo objetivou investidas o tamanho e a taxa de crescimento de regenerantes (juvenil e plântulas) de Commiphora leptophoeos entre florestas de caatinga jovem e madura durante a estação chuvosa.

\footnotetext{
${ }^{1}$ Doutorado em Botânica, Universidade Federal Rural de Pernambuco, vanessa.rodriguesdearaujo@gmail.com ${ }^{2}$ Doutor, Universidade Federal Rural de Pernambuco.

${ }^{3}$ Doutor, Universidade Federal de Pernambuco-Centro Acadêmico de Vitória
} 


\section{Fundamentação Teórica}

O crescimento de uma planta é determinado pelo incremento em biomassa do indivíduo, resultando em aumento do seu tamanho, vertical ou horizontalmente, por consequência do alongamento celular nos tecidos vegetais (PEIXOTO et al., 2011). Evidenciando que o crescimento em altura e diâmetro de uma planta, está relacionado com seus caracteres morfológicos, físiológicos e comportamentais, tais como o quantitativo de biomassa acima do solo, tamanho do enraizamento, propagação lateral e tamanho foliar, nos diferentes estádios do seu ciclo de vida (SILVA; NOGUEIRA, 2003; PEIXOTO et al., 2011).

Além disso, a identificação das taxas de crescimento de cada planta permite predizer informações de grande importância para trabalhos de recolonização de áreas degradas, predizendo a melhor espécie para recolonizar determinadas áreas, visto que as de maior taxa de crescimento provavelmente serão melhores para a recolonização de uma área (LOPEZ-IGLESIAS et al., 2014).

No entanto, vários fatores ambientais e intrínsecos a planta, podem influenciar no seu crescimento, aumentando ou reduzindo o processo de diferenciação celular dos tecidos vegetais, tais como disponibilidade e intensidade luminosa, disponibilidade de água e nutrientes no ambiente e relações ecológicas como a competição e o parasitismo (QUEIROGA et al., 2003; MENDIVELSO et al., 2014).

Esses fatores bióticos e abióticos atuando em conjunto ou isolados no ambiente são de grande importância para explicar o crescimento do vegetal, visto que, eles exercem forte influência na taxa de crescimento da planta, no tempo e no espaço (ARAÚJO et al., 2008b; ARAÚJO et al., 2010).

Diante disso, estudos que busquem compreender as respostas de crescimento das espécies as condições de variações da disponibilidade de água e de diferentes intensidades de luz, que essas florestas recebem ao longo do ano, são de grande importância para estudos que visam a recuperação de florestas que foram perturbadas e tiveram suas condições ambientais modificadas. Visto que, tais estudos auxiliam na identificação das taxas de crescimento nos diferentes estádios ontogenéticos da planta. E consequentemente, na previsão do tempo necessário para completar a recuperação de florestas, que sofreram alterações (SILVA et al., 2012). 


\section{Metodologia}

Área de Estudo: O estudo foi desenvolvido em duas florestas de idades sucessionais

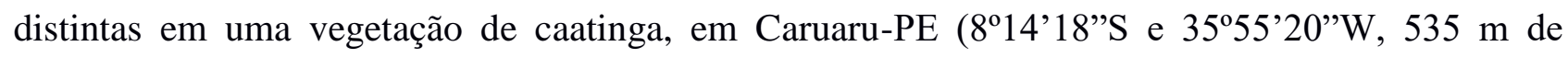
altitude). A primeira floresta possui mais de 50 anos de preservação, não sendo permitidas atividades de pastagem, madeireira ou agrícola, e com histórico de perturbação desconhecido, sendo considerada uma floresta madura. E a segunda é uma floresta jovem com 20 anos de regeneração natural, após corte manual da vegetação para cultivo experimental Opuntia ficus-indica Mill., sem adição de fertilizantes e uso do fogo. Tais florestas estão separados por uma estrada de barro e distam cerca de $5 \mathrm{~m}$ uma da outra.

A estação chuvosa geralmente ocorre no período entre março a agosto e os demais meses são marcados pela seca. Todavia, podem ocorrer eventuais chuvas na estação seca, bem como veranicos na estação chuvosa. A precipitação no ano do estudo (2014) foi de 509,6 mm.

Espécie selecionada: Para o estudo selecionou-se a espécie Commiphora leptophoeos, comumente encontradas nas florestas em estágio mais avançado de regeneração, em áreas mais preservadas (QUEIROZ et al., 2006). De acordo com a literatura, ela é bem representativa em ecossistemas da caatinga, possuindo alto valor de importância tanto para os processos ecológicos como para a economia local, sendo bastante utilizadas para construção, fabricação de utensílios e medicamento.

Coleta de dados: Para verificar o tamanho do indivíduo e a taxa de crescimento da planta foram selecionados ao final do estudo 20 indivíduos de cada estádio ontogenético nas duas florestas totalizando 80 indivíduos. Dos quais, foram mensurados o tamanho do caule (diâmetro basal e comprimento total) no início (março/2014) e final (agosto/2014) da estação climática chuvosa, com auxílio de paquímetro e trena. A medição foi feita ao nível do solo no caule do indivíduo. Para a identificação dos estádios ontogenéticos juvenil e plântula utilizou-se como base as características morfológicas externas de Araújo et al. (2008b).

Análise dos dados: Determinou-se a taxa de crescimento pela diferença no tamanho (t) dos indivíduos (altura e diâmetro) e o intervalo de tempo de medição. A análise do crescimento em altura e diâmetro foi apresentada apenas para os indivíduos que sobreviveram durante o tempo do estudo.

Diferenças no tamanho em altura e em diâmetro dos indivíduos, nas taxas de crescimento absoluto médio em diâmetro e em altura entre as florestas jovem e madura, para cada estádio 
ontogenético (plântula e juvenil) e espécie, foram verificadas pela análise de Kruskal-Wallis, com teste de Student-Newman-Kleus a posteriori no programa BioEstat 5.0.

\section{Resultados e Discussões}

Nesse estudo, observamos que a maioria das plântulas apresentaram taxa de crescimento em diâmetro (65\% dos indivíduos) e taxa de crescimento em altura (65\% dos indivíduos) nas duas florestas. Enquanto que, para os juvenis a taxa de crescimento em diâmetro foi nula ou negativa para (66\% dos indivíduos) dos indivíduos na floresta jovem e (30\% dos indivíduos) na floresta madura, e a taxa de crescimento em altura obteve valores positiva para cerca de (64\% dos indivíduos) dos indivíduos nas duas florestas.

Foram observadas diferenças significativas no tamanho inicial e final entre as florestas para os juvenis quanto ao diâmetro e altura, com maiores tamanhos na floresta jovem, e para as plântulas houve diferença apenas para o diâmetro, com maiores tamanhos para a floresta jovem.

De acordo com Carvalho et al. (2012), nas florestas secas, do tipo caatinga, a luz não funciona como um fator limitante do crescimento das plantas lenhosas porque as florestas de caatinga não apresentam dossel contínuo. Contudo, florestas jovens apresentam a estrutura da copa das árvores bastante descontinua com relação a floresta madura, em virtude do menor número de lenhosas na idade adulta (LOPES, et al., 2012), permitindo, portanto, que uma maior incidência de luz alcance o interior de uma floresta jovem e atinja os regenerantes do estrato lenhoso da vegetação.

Associando a esse fato estudos apontam que C. leptophloeos apresenta madeira de baixa densidade e que acumula muita água em seus tecidos (LIMA et al., 2012), embora possua um crescimento lento e pertencer ao grupo das espécies sucessionais mais tardio (QUEIROZ et al., 2006). Assim, tal fato tenha possibilitado que os regenerantes dessa espécie apresentassem maior tamanho na floresta jovem, podendo ser indicado como uma estratégia de ocupação de espaços abertos, encontrados em florestas jovens.

Com relação a taxa de crescimento absoluta mensal em diâmetro e em altura não foram encontradas diferenças entre as florestas para ambos os estádios ontogenético. Evidenciando que, mesmo sobre condições ambientais distintas quanto a disponibilidade do recurso os regenerantes de C. leptophloeos desenvolvem em cada ambiente ajuste para que seus processos metabólicos não 
sejam alterados significativamente, ou que essas variações não sejam suficientes para que ocorram alterações no metabolismo do vegetal.

\section{Conclusões}

Por fim, as expectativas de ocorrer diferenças na taxa de crescimento entre as florestas jovem e madura não foi confirmada. Todavia, pudemos observar que os tamanhos iniciais e finais dos indivíduos diferiram entre as mesmas, o que pode ressaltar que para que os regenerantes da espécie C. leptophloeos estabeleçam-se em uma floresta jovem necessitam apresentar maiores tamanho de altura.

\section{Referências}

ARAÚJO, E.L.; NOGUEIRA, R.J.M.C.; SILVA, S.I.; SILVA, K.A.; SANTOS, A.V.C.; SANTIAGO, G.A. Ecofisiologia de plantas da caatinga e implicações na dinâmica das populações e do ecossistema. In: MOURA, A.N., ARAÚJO, E.L., ALBUQUERQUE, U.P. (Eds.), Biodiversidade, potencial econômico e processos eco-fisiológicos em ecossistemas nordestinos. NUPEEA, v. 1, 2008a. p. 329-361.

ARAÚJO, E.L.; MARTINS, F.R.; SANTOS, F.A.M. Ontogenia e variações alométricas na relação comprimento-diâmetro do caule em plantas lenhosas da caatinga. In: ALBUQUERQUE, U.P.; MOURA, A.N.; ARAÚJO, E.L. (Eds.). Biodiversidade, potencial econômico e processos ecofisiológicos em ecossistemas nordestinos. NUPEEA, v. 1, 2008b. p. 81-104.

ARAÚJO, E.L.; MARTINS, F.R.; SANTOS, F.A.M. Estádios ontogenéticos e variações no crescimento anual do caule de duas espécies lenhosas em uma área de vegetação de caatinga, Pernambuco, Brasil. In: MOURA, A.N.; ARAÚJO, E.L.; ALBUQUERQUE, U.P. (Eds.). Biodiversidade, potencial econômico e processos ecofisiológicos em ecossistemas nordestinos. NUPEEA, v. 1, 2010. p. 387-410.

CARVALHO, N.O.S.; PELACANI, C.R.; RODRIGUES, M.O.S.; CREPALDI, I.C. Crescimento inicial de plantas de licuri (Syagrus coronata (MART.) BECC.) em diferentes níveis de luminosidade. Revista Árvore, v. 30, n. 3, p. 351-357, 2006.

DOLOSO, D.M.; HOLSBACK-MENEGUCCI, Z.R.; SANTIAGO, E.F. Efeitos da radiação ultravioleta-C sobre a simetria e morfoanatomia foliar de Rapanea ferruginea (Ruiz et. Pav) Mez. (Myrsinaceae). Acta Scientiarum Biological Sciences, v. 31, n. 2, p. 165-172, 2009.

LIMA, A.L.A.; SAMPAIO, E.V.S.B.; CASTRO, C.C.; RODAL, M.J.N.; ANTONINO, A.C.D.; MELO, A.L. Do the phenology and functional stem attributes of woody species allow for the identification of functional groups in the semiarid region of Brazil? Trees, v. 26, p. 1605-1616, 2012.

LOPES, C.G.R.; FERRAZ, E.M.N.; CASTRO, C.C.; LIMA, E.N.; SANTOS, J.M.F.F; D.M., SANTOS.; ARAÚJO, E.L. Forest succession and distance from preserved patches in the Brazilian semiarid region. Forest Ecology and Management, v. 271, n. 1, p. 115-123, 2012.

LOPEZ-IGLESIAS, B.; VILLAR, R.; POORTER, L. Functional traits predict drought performance and 
distribution of Mediterranean woody species. Acta Oecologica, v. 56, n. 1, p. 10-18, 2014.

PEIXOTO, C.P.; CRUZ, T.V.D.; PEIXOTO, M.F.S.P. Análise quantitativa do crescimento de plantas: conceito e práticas. Enciclopédia biosfera, v. 2, n. 13, p. 51-76, 2011.

PEREIRA, I.M.; ANDRADE, L.A.; COSTA, J.R.; DIAS, J.M. Regeneração natural em um remanescente de caatinga sob diferentes níveis de perturbação, no agreste paraibano. Acta Botanica Brasilica, v. 15, n. 3, p. 413-426, 2001.

QUEIROGA, J.L.; ROMANO, E.D.U.; SOUZA, J.R.P.; MIGLIORANZA, E. Estimativa da área foliar do feijão-vagem (Phaseolus vulgaris L.) por meio da largura máxima do folíolo central. Horticultura Brasileira, v. 21, n. 1, p. 64-68, 2003.

QUEIROZ, J.A., TROVÃO, D.M.B.M., OLIVEIRA, A.B., OLIVEIRA, E.C.S. 2006. Análise da estrutura fitossociológica da Serra do Monte, Boqueirão, Paraíba. Revista de Biologia e Ciências da Terra. v. 6, p. 251-259, 2006.

MENDIVELSO, H.A.; CAMARERO, J.J.; GUTIÉRREZ, E.; ZUIDEMA, P.A. Time-dependent effects of climate and drought on tree growth in a Neotropical dry forest: Short-term tolerance vs. long-term sensitivity. Agricultural and Forest Meteorology, v. 188, n. 1, p. 13-23, 2014.

SILVA, S.O.; FERREIRA, R.L.C.; SILVA, J.A.A; LIRA, M.A.; ALVES JUNIOR, F.T.; CANO, M.O.O.; TORRES, J.E.L. Regeneração natural em um remanescente de caatinga com diferentes históricos de uso no agreste pernambucano. Revista Árvore, v. 36, n. 3, p. 441-450, 2012.

SILVA, E.C.; NOGUEIRA, R.J.M.C. Crescimento de quatro espécies lenhosas cultivadas sob estresse hídrico em casa-de-vegetação. Revista Ceres, v. 50 , n. 288, p. 203-217, 2003.

ZHU, S; SONG, J.; LI, R.; YE, Q. Plant Hydraulic and photosynthesis of 34 woody species from different 